\title{
Factors Behind Ruined Communication in Contemporary Marriages
}

\author{
Maryam Suleiman Jamo \\ Eastern Mediterranean University, Famagusta, Northern Turkey, Postal Code: 99450
}

\begin{abstract}
Appreciating the significance of communication to every solid relationship, its importance to intimate relationship such as marital union can never be overemphasized. In fact, A marriage without effective communication among the spouse is likely to crumble like a pack of cards. Communication often regarded as the life wire of marital relationship is been threatens by some factors. This paper relied on existing literature to conceptually explicate the forces behind ruined communication in contemporary marriages. The contemporary world is seeing the evolvement of some forces that ruined effective communication flow in marriage. Cultural friction, intercultural relationship, extended family influence, poor communication skills, language barrier, communication defects and distraction from ICT are some of the identified factors that can cause ruined communication in marriage. Therefore, for couples to enjoy communication flow in their marital affairs, it is important that they understood these factors and how they can be avoided.
\end{abstract}

Keywords: communication, interpersonal communication, marriage, and ruined communication

DOI: $10.7176 / \mathrm{NMMC} / 81-04$

Publication date:June $30^{\text {th }} 2019$

\section{Introduction}

Communication is a tool that binds human being to coexist together from time immemorial. However, communication is a dynamic process that is said not to be complete until both sender and receiver become active participants. This is why different definitions and models of communication accord much importance to feedback in communication. Through communication individuals that need to foster union or understanding knows the importance of interaction. It is a common knowledge that it is through communication that individuals or group of people will know if they have a common interest or not. Also, it is communication that set the basis for people if they are pursuing a common goal; as such, couples understand their relationship through communication.

Marriage cannot be instituted outside communication. Through interpersonal communication, two individuals get to know how compatible they to form a union in marriage. As Abela, Frosh and Dowling (2005) noted in their study, open communication in the bedrock of solidifies marriage and that lack of it can lead to marriage dissolution. Mackey, Diemer, and O'Brien (2000) noted the importance of interactive communication in marriage and not just listening to one another but also understanding one another's needs and how they are met in the relationship. It is imperative to know that communication serves as ways to identify the roles and expectations in an effort to have a better understanding of the individual, be more empathetic, and exhibit greater respect. In this way, spouses can increase their respect for one another while also building on their mate's strengths.

However, there seem to be factors that can lead to ruined communication in marriage. For instance, Renalds (2011) identify intercultural friction and language barrier can be an obstacle to a harmonious marriage. On their part, Esere, Yusuf and Omotosho (2011) stressed the importance of spousal communication to marital stability. That is, a ruin in communication is a threat to a stable marriage. Now studies (Ngunan \& Regina, 2016; Alt \& Boniel-Nissi, 2018; Aydun, Sari \& Sahin, 2018) have confirmed that the filtration of web 2.0 and its members such as the social media into our homes is deterring effective communication among families. Thus, seeing the importance of communication to marriages, this paper is positioned to explore the forces behind ruined in communication among marriages in contemporary times. It is imperative to interrogate literature and document the factors that ruined communication in marriage; because the society that desires healthy marriages need to know how to mitigate barriers to effective communication among marital union. Also, research into the ways the internet is deterring family interpersonal relationship is rare (Dunu \& Ugbo, 2017); and now forces that ruined communication in marriage is an issue that worth investigating.

\section{Communication}

Communication is no doubt central to our everyday interactivity and ideas about what makes life worth living. Communication is the process by which we understand others and in turn endeavor to be understood by them (Gudykunst \& Nishida, 2001). It is dynamic, constantly changing and shifting in response to the environmental situation (Paxson, 2011). Communication is all of the procedures by which one mind can affect another and must especially when there is common interest. Communication means that information is passed from one mind to another.

Communication is also conceived in the article as an exchange of ideas, an interactive process that works in 
a circular, dynamic and ongoing way. The article stressed that communication is far from the linear transmission of information which implies talking with people. Rather, it is talking with people, a process of social interactions through messages and symbols.

We live in a world were by individuals or participants in an interpersonal interaction tend to influence another to be believed. Sometimes we can go further to engage in deception just to gain credibility. This is done to ensure that the mutual understanding that exists between the sender and receiver in the communication process is maintained and sustained.

However, mutual understanding among two individuals can be ruined, must especially if there is ruined in communication. That is, a communication gap can result in conflict. Therefore, mutual benefits can be maintained through effective communication. "Communication is effective to the extent that the person interpreting the message attaches a meaning to the message that is relatively similar to what was intended by the person transmitting it" (Gudykunst \& Nishida, 2001, p. 60).

\section{Contemporary Marriages}

The marriage is an institution that is as old as the creation of man. Marriage dates back to the first human on earth. It is an indispensable phenomenon in human life regardless of society, tribe and religious affiliations. Some scholars such as Munroe (2003), see marriage as a religious duty and is consequently a social necessity as well as a moral safeguard. Marriage is the oldest social institution ordained by the God and in some clime sanction by the society as a social contract between two individuals to become husband and wife. Marriage, as ordained by God or accepted by the society, gives legitimacy to sexual relationship and reproduction for legitimate children (Sarker, 2007). Marriage is the state of being united with a person of the opposite sex as husband or wife for the purpose of harmonious living, companionship, procreation and maintaining a family (Gove, 2006).

However, marital instability has become a thing of concern in this contemporary society and this is associated with single parenting, divorce, separation, and widowhood. Single parenting, separation, and divorce sometimes necessitated as a result of conflict of interest are social phenomena created by either husband or the wife or both, but widowhood is beyond the control of human being, it is related to death and thus universal (Amina 2008).

In today's contemporary society, the face of marital intimate relationships is changing. Deep bonds between persons of diverse cultures or traditions are becoming more common and intercultural marriages are on the rise (Waldman \& Rubalcava, 2005; Frame, 2004), due to urbanization and migration. Now, it is common to see marriages across the ethnic, religious, linguistic and racial line.

\section{Conflict in Marriages}

Marriage involves a union of two individuals, commonly husband and wife who are embarking on the occasionally arduous, novel endeavor of becoming one in interest. Thus, when a bridge of interest surfaced, conflict emerges. The differences in views, beliefs, actions or inactions may begin surfacing at an increased rate even during the early days of marriage. A new couple must individually and jointly construct a solution for significant differences as these conflicts possess the power to endanger the stability and marital satisfaction within the union (Tallman \& Hsiao, 2004).

Oduro-Frimpong (2007) study found that married couples exhibited some form of conflict within their union. In intimate relationships, conflict is a common phenomenon and does not have to drive partners apart. The reasons for conflict can be diverse. Tallman and Hsiao (2004) maintained that conflict develops partially due to individuals ' expectations that their partners will fulfill their social, emotional, and material needs throughout their married life and if that seems not to be fulfilled can result to grievances. Allender and Longman (2009) reported that since male and female have similar and dissimilar interest and social wants, the differences inherent in gender may be a huge potential for conflict and contempt.

In a conjugal relationship, individuals are intimate with one another and thus can easily become vulnerable. Therefore, a spouse's words, actions, inactions, beliefs, wants to carry greater weight with his or her partner. A spouse has the capability to provoke or increased feelings or passion from his or her spouse. At times, the susceptibility and familiarity within this relationship create a potential for increased conflict.

All marriages involve a blending of two distinct lives with a different childhood history, a personality, values, and expectations. Gottman, Driver, and Tabares, (2002: 387) called this the "active creation of a new culture that has never existed before". However, through communication, two individuals that have initially agreed to be husband and wife will initiate a common ground.

However, the conflict in communication that may ensue based on the fusion and may be constructive and productive. Rosen-Grandon, Myers, and Hattie (2004) found that when married couples were able to manage conflict along with various marital roles, they were able to arrive at marital satisfaction through shared values. Marital satisfaction develops due to loyalty, love, and shared values. For married couples to arrive at marital satisfaction through love, communication and expression of affection are critical (Rosen-Grandon et al., 2004) for marriage survival. 


\section{Significance of Communication in Marriages}

A marriage without effective communication among the spouse is likely to crumble. Communication is regarded as the life wire of marriage relationship or any other meaningful relationship that needs to endure (Esere, 2002, 2006). Communication is the medicine for ailing matrimonial relationship (Olagunju \& Eweniyi, 2002). With so many marriages ending tragically in separation or divorce (Adegoke \& Esere, 1998), it is more important now to work on the communication between husband and wife.

A myriad of problems escalate when there is no communication, and many problems are resolved when there is effective communication among partners. For sure, communication is the key to a successful marriage, and without communication, no marriage can survive in this divorced filled contemporary society (Jolin, 2007).

Toward this end, this article is aimed at investigating the forces that ruined communication on marriage. Communication is very essential in stabilizing and maintaining a marriage. Communicating effectively takes practice and a great deal of effort to achieve. Without communication, it is nearly impossible to resolve conflicts or grow a relationship or partnership.

Communication is seen by Hybels and Weaver (2001) as any process in which people share information, ideas, and feelings which involve not only the spoken and written word but also body language, personal mannerisms, and style. Communication is an integral feature of human activities. It is a pillar which maintains the structure of peaceful coexistence and mutual understanding.

Communication is very vital in all areas of human life especially the marriage relationship (Esere, 2008). Communication is the key to a strong, healthy relationship. It allows partners to feel love and caring. Effective communication requires the practice of the skills of listening and expressing thoughts and feelings.

According to Idowu and Esere (2007), more than half of the failed relationships are due to the fact that there severe lack of communication between couples. to have a lasting relationship with someone, one must have excellent communication skills. One must be able to convey one's emotions and thoughts, as well as being able to absorb one's partner's emotions and thoughts. The art is probably even then the art of talking.

Couples will learn and grow far more in their relationships if they sit down and listen to their partners, instead of talking and voicing all of their opinions at once. This is not to say that one will not voice one's opinions. But one must listen to the other's opinions as well and take them into consideration. Some people do not communicate with words, they communicate through actions. If one pays close attention, one will get what he/she wants from his/her partner. But the problem is, most couples do not pay close attention to each other, thereby causing marital disharmony. In this study, an attempt will be made to investigate the forces that ruined communication in marriage. This study is pertinent especially at the wake of increases in marital instability in this contemporary world.

\section{Factors that Causes Ruined Communication in Marriages}

Having noted the importance of communication to a successful marriage, it is pertinent to also note that there are emerging trends in the society that are affecting effective communication in marital union. For instance, cultural friction is an issue that those that engage in intercultural marriage faced with. Renalds (2011) study found that language fluency influences the efficacy of communication within intimate relationships in America. His findings suggested that language is significant to effective communication in intercultural marriages. Perhaps this is true because of the complex relationship between language and culture.

Renalds (2011) equally found that cultures tend to communicate using a high-context or low-context dimension. As the terms imply, some communication relies more on the context to communicate meaning. That multiple spouse recognized these differences in communication, although the root of these differences is perhaps less easy to identify and accept.

Extended family is another factor that can ruined communication in marriage. Renalds (2011) noted that intercultural marriages are the union of not only two individuals with distinct cultures, but also the merger of mothers, fathers, siblings, cousins, aunts, uncles, and other relatives from diverse cultures. Such a coalition has the potential for harmonious gatherings and blossoming relationships as well as tumultuous encounters and hurtful exchanges. Conflicting of family interest and expectation on their siblings' marriage can ruin effective communication among spouse.

Communication defects are a factor that can ruin effective communication in marriage. Olaniyi (2015) empirical finding found that "in fellowship, there is communion, communication, and togetherness". This is promoted when the family does things in common and in togetherness. Esere, Yusuf and Omotosho (2011) study found that lack of effective communication is a bane to marital stability. They equally found a significant difference in the perception of married adults on the influence of spousal communication on marital stability on the basis of gender and length of years in marriage.

Poor communication skills can cause irrevocable damage to relationships; affecting productivity, satisfaction, performance, morale, trust, respect, self -confidence, and even physical or mental health. Effective communication in marriage is vital to a happy marriage and family life. Ineffective communication is a common problem complaint of couples who are having difficulties (Esere \& Idowu, 2000). 
Ineffective communication can lead to numerous family problems, including excessive family conflict, ineffective problem8solving skill, lack of intimacy, soon. Poor communication style is also associated with an increased risk of divorce and marital separation (Esere, 2008).

Learning to communicate involves hard work and as the divorce rate shows, many couples are unable to reach this level of understanding and therefore issues are left unresolved and tension deepens leading to a lack of understanding and respect. Ultimately, this may lead to couples simply dissolving the relationship for lack of knowing how to fix the problems.

This is because divorce is becoming a rampant act. Several submission have been presented in the past decade to explain the enhancement or the deterioration of quality of couple's relationship such as those by Yusuf (2005), which focused on indices of marital instability, Adeyemi (1991), worked on causes of divorce and separation, Isiaka (2005) empirically investigated relationship between divorce and spousal communication and found that lack of effective communication in marriage precedes divorce

Infiltration of the internet into our private lives' and consuming most of our time daily is a serious threat that can ruined communication in marriage. Several studies (Ngunan \& Regina, 2016; Alt \& Boniel-Nissim, 2018; Aydun, Sari \& Sahin, 2018) founds that the internet has a strong potential of disrupting family communion. Ngunan and Regina (2018) noted that ICT is establishing a gap in communication at home. Aydun, Sari \& Sahin, (2018) study concludes that social media affect marriages negatively.

Ngunan and Regina (2018) study found that technology has created a gap in interpersonal communication amongst family relationships and that people lose interest in communicating interpersonally with family members due to constant engagement in Information and Communication Technologies (ICTs).

\section{Conclusion}

The importance and benefits of communication to intimate relationship such as marital union can never be overemphasized. Idowu and Esere (2007) understood this fact succinctly when they pointed out that more than half of the failed relationships are due to the fact that there was a severe lack of communication between couples. It is now a priori that for a long and lasting relationship with someone, one must have a good appreciation of the position of communication in the relationship. A marriage without effective communication among the spouse is likely to crumble like a park of the card. Communication is regarded as the life wire of marriage relationship or any other meaningful relationship that needs to last (Esere, 2002, 2006). Communication is the medicine for ailing matrimonial relationship (Olagunju \& Eweniyi, 2002). However, the contemporary world is seeing the evolvement of some forces that ruined effective communication flow in marriage. Cultural friction, intercultural relationship, extended family influence, poor communication skills, language barrier, communication defects and distraction from ICT are some of the identified factors that can cause ruined communication in marriage. Therefore, for couples to enjoy communication flow in their marital affairs, it is important that they understood these factors and how they can be avoided.

\section{References}

Abela, A., Frosh, S., \& Dowling, E. (2005). Uncovering beliefs embedded in the culture and its implications for practice: The case of Maltese married couples. The Association for Family Therapy and Systemic Practice, 27, 3-23. Retrieved from http://search.ebscohost.com.ezproxy.liberty.edu:2048/login.aspx?direct=true \&db=eoah\&AN=6763559\&site $=$ ehost-live\&scope $=$ site

Adegoke, A. A. \& Esere, M. O. (1998). Sources of stress and coping strategies among divorcees in Ilorin Metropolis. The Counsellor: Journal of the Counselling Association of Nigeria, 16(1), 227 - 233.

Adeyemi, E. (1991). Causes of divorce and separation as perceived by married couples in Tertiary institutions Ilorin metropolis. Unpublished M. Ed. project, University of Ilorin.

Allender, D., \& Longman, T. (2009). The intimate mystery. Downers Grove, IL: InterVarsity.

Alt, D. \& Boniel-Nissim, M. (2018). Parent-adolescent communication and problematic internet use: The mediating role of fear of missing out (FOMO). Journal of Family Issues, $1 \quad-19$. ps://doi.org/10.1177/0192513X18783493

Anima, R. N. (2008). Marital instability and its impact on women and children of Bangladesh. Shahid Sharawardi College Laxmibazar, Dhaka, Bangladesh

Aydun, B., Sari, S.V., \& Sahin, M. (2018). The effect of social networking on the divorce process. Universal Journal of Psychology 6(1), 1-8. DOI: 10.13189/ujp.2018 .0 60101

Dunu, I.V \& Ugo, G.O. (2017). Separated household? Effects of personalized communication devices on Nigerian Families' communication pattern. New Media and Mass Communication, 60, 28-40.

Esere, M.O., Yusuf, J. \& Omotosho, J.A. (2011). Influence of spousal communication on marital stability: Implication for conducive home environment. Edo Journal of Counselling, 4 (1\& 2), 50-61.

Esere, M. O. (2008). Communication in marriage relationship. In L.A. Yahaya, M.O. Esere, J. O. Ogunsanmi, \& 
A. O. Oniye (2008). Marriage, sex and family counseling. Ilorin: Unilorin Press Ltd.

Esere, M. O. \& Idowu, A. I. (2000). Effects of cognitive restructuring in resolving marital conflicts among selected couples in Ilorin. Nigerian Journal of Applied Psychology, 6(1), 87898.

Frame, M. (2004). The challenges of intercultural marriage: Strategies for pastoral care. Pastoral Psychology, 52 (3), 219-232. Retrieved from http://search.ebscohost. com.ezproxy.liberty.edu:2048/login.aspx?direct=true\&db=sih\&AN=11762806\&site=ehost-live \&scope=site

Gottman, J, Driver, J, \& Tabares, A. (2002). Building the sound marital house: An empirically derived couple therapy. In Alan S. Gurman and Neil S. Jacobson (Eds.), Clinical handbook of couple therapy (pp. 373-399). New York, NY: Guilford.

Gove, B (2006). Webster's Third New International Dictionary of The English Language Unabridged. U.S.A. Marrian-Webster Inc.

Gudykunst, W.B., \& Nishida, T. (2001). Anxiety, uncertainty, and perceived effectiveness of communication across relationships and cultures. International Journal of Intercultural Relations, 25, 55-71.

Hybels, S. A. \& Weaver, A. C. (2001). Communicating effectively. Boston: Glencoe McGraw8Hill.

Idowu, A. I. \& Esere, M. O. (2007). counseling: A multidimensional perspective. Ilorin: Tim Sal Publishers.

Isiaka, A. A. (2005). between spousal communication and divorce. Unpublished Masters Project University of Ilorin, Nigeria.

Jolin, K. (2007). Ways to encourage communication between your spouse and you. San Diego: Academic Press.

Mackey, R., Diemer, M., \& O‘Brien, B. (2000). Conflict-management styles of spouses in lasting marriages. Psychotherapy 37 (2), 134-148. doi:10.1037/h0087735

Munroe, M. (2003). woman's communication style: Promoting positive Muslim marital relations. A Journal of Sound Islamic Thoughts, 1(1), 46851.

Ngunan, A. P., \& Regina, O. (2016). Digital divide: a gap in interpersonal communication amongst Nigerian family relationship. GSTF Journal on Media \& Communications (JMC), 3 (1), 16-22.DOI: 10.5176/2335$6618 \quad 3.1 .44$

Oduro-Frimpong, J. (2007). Semiotic silence: Its use as a conflict-management strategy in intimate relationships. Semiotica 167(1-4), 283-308. doi:10.1515/SEM.2007.080.

Olaniyi, A.A. (2015). Analytical study of the causal factors of divorce in African homes. Research on Humanities and Social Sciences, 5(14), 18-29.

Olagunju, O. P. \& Eweniyi, G. B. (2002). Communication: A strategy in conflict resolution among organizational workers. The Counsellor, 19(1), 66-78.

Parker S (1991). Informal Marriage, Cohabitation, And the Law. In Am. J. Soci., 96: 6 Ed. Parish LW New York. University of Chicago Press, p. 1588.

Paxson, P. (2010). Mass Communication and Media Studies: An Introduction. London: The Continuum International Publishing Group Ltd

Renalds, T.G. (2011). Communication in intercultural marriages: Managing cultural differences and conflict for marital satisfaction. Unpublished Thesis, Liberty University, Lynchburg, Virginia

Rosen-Grandon, J., Myers, J., \& Hattie, J. (2004). The relationship between marital characteristics, marital interaction processes, and marital satisfaction. Journal of Counseling and Development, 82, 58-68. Retrieved from

http://search.ebscohost. com.ezproxy.liberty.edu:2048/login.aspx?direct=true \&db=a9h\&AN=12340410\&site=ehostlive\&scope $=$ site

Tallman, I., \& Hsiao, Y-L. (2004). Resources, cooperation, and problem-solving in early marriage. Social Psychology Quarterly 67, 172-188. Retrieved from http://search. ebscohost.com.ezproxy.liberty.edu:2048/login.aspx?direct=true \&db=eoah\&AN=7394540\&site=ehostlive\&scope $=$ site

Waldman, K., \& Rubalcava, L. (2005). Psychotherapy with intercultural couples: a contemporary psychodynamic approach. American Journal of Psychotherapy, 59 (3), 227-245. Retrieved from http://search.ebscohost.com.ezproxy.

2048/login.aspx?direct=true $\& \mathrm{db}=\mathrm{a} 9 \mathrm{~h} \& \mathrm{AN}=19311260 \&$ site=ehost-live $\&$ scope $=$ site

Yusuf, S. T. (2005). Indices of marital perceived by University of Ilorin lecturers. Unpublished B.Ed. the project, University of Ilorin, Nigeria. 